\title{
La gracia como posibilidad del encuentro entre Dios y el hombre en la obra De visione Dei de Nicolás de Cusa
}

\author{
LORENA BASUALTO PORRA \\ Pontificia Universidad Católica de Valparaíso (Chile) \\ lorenabasualto@yahoo.es
}

\begin{abstract}
Resumen
El artículo presenta los aportes más importantes y significativos de la gracia en Nicolás de Cusa específicamente en la obra De visione Dei, en torno al tema de la gracia como posibilidad del encuentro entre Dios y el hombre. Específicamente se tratará el tema de la gracia en torno a tres dimensiones: en tanto gracia de Dios en la dinámica del rostro, del hombre como ser agraciado en relación constitutiva con Dios y los frutos que la gracia realiza en cada ser humano. A su vez el escrito pretende ser un aporte a la renovación del tratado de gracia en orden a la mística, por lo que se propone un esbozo sistemático en orden a la posibilidad del encuentro desde la dimensión ontológica, gnoseológica y escatológica.
\end{abstract}

Palabras clave: Gracia, rostro de Dios, hombre, gloria, visión de Dios.

\section{The Grace as a possibility of the encounter among God and Man, in De visione Dei piece of work by Nicholas of Cusa}

\begin{abstract}
The article presents the most important and significant contribution of the Grace in Nicolas de Cusa, specifically in the piece of work. 'De Visione Dei', related to the subject of the Grace as a possibility of the encounter among God and Man. Specifically it will deal with the matter of Grace in three dimensions: as a God's grace in the face dynamic, of man as a graceful being in a constituent relationship with God and the fruits that the grace makes in every buman being. At the same time, the book pretends to be a contribution to the renovation of the treatise of grace related to the mysticism, that's why it shows a systematic outline in order to the possibility of the encounter from the ontological, epistemological and eschatological dimension.
\end{abstract}

Key words: Grace, face of God, man, glory, vision of God.

Magister en Teología Dogmática por la Pontificia Universidad Católica de Chile. Profesora Instituto de Ciencias Religiosas (Ad Instar Facultatis), Pontificia Universidad Católica de Valparaíso. Este artículo es una síntesis de la Tesis presentada en la Facultad de Teología de la Pontificia Universidad Católica de Chile para obtener el grado de Magister en Teología Dogmática. Esta investigación ha sido realizada con el patrocinio de Stipendienwerk Lateinamerika-Deutshland, a través de su Consejo de Valparaíso. 


\section{Introducción}

A la pronta conmemoración de los 50 años de convocación del Concilio Vaticano II es innegable afirmar que éste dio lugar al nacimiento de una renovada teología católica nueva, fresca y de una gran riqueza intelectual (García, 2006: 519). A pesar de esto, a nivel de los ambientes teológicos, y específicamente en lo que se refiere al tratado De gratia, queda más bien la percepción que este pasa por una situación crítica $^{1}$. Esto, principalmente debido a la ausencia de una reformulación contemporánea de la gracia que permita cubrir los vacíos conceptuales, teóricos y prácticos, para facilitar una mejor comprensión del diálogo entre Dios y el hombre, a la luz de la fe, en el contexto de la sociedad actual (Cabrié, 2005: 150).

De este modo el Concilio impulsa una renovación de la teología de la gracia que, según Rahner (1973: 319-334), debería darse en el contexto de la antropología del hombre redimido y justificado, de modo de no hablar de una forma abstracta de la gracia, sino del hombre agraciado. Por tanto, convendría hacer esfuerzos por realizar un tratado donde se subraye la doctrina sobre la gracia que diviniza y perdona al hombre en todas las dimensiones de su vida.

Junto a este contexto teológico contemporáneo, se debe considerar también la dificultad que existe para el hombre actual: la aceptación de la gracia como un don inmerecido. Lo anterior se da principalmente por el hecho que existe una concepción del hombre muy marcada por la civilización técnico-científica y por la competitiva cultura consumista, donde se profesa la ideología de la eficacia y de la autosuficiencia. En este tejido social, la idea de realización humana es entendida desde el mismo hombre, de allí que pronunciar un mensaje al hombre moderno que sostiene el don y lo gratuito, le suene más bien a escándalo y a locura. Además, en este contexto, no se entiende un anuncio de la gracia como puro amor de Dios, el cual en cuanto amor es indemostrable y en cuanto Dios improbable (Ruiz de la Peña, 1991: 201-202, 310).

En medio de estas problemáticas: ¿qué podría aportar el estudio de un autor del siglo XV con respecto al tema de la gracia? Este cuestionamiento surge a raíz del lugar que ocupa Nicolás de Cusa (González, 2001: 11-14) dentro de la historia de este tratado, ya que no se encuentra en los grandes momentos del progreso de este saber

\footnotetext{
$1 \quad$ El tratado De gratia nace alrededor del año 1680 en torno al Concilio de Trento a partir de la clarificación de la gracia como justificación en la línea de la teología medieval. Con respecto a la crisis de la gracia como tratado puede verse un recorrido histórico de esta problemática en Meis (1990: 227-255).
} 
teológico pues, es sabido que principalmente éste gira en torno a dos grandes hitos: la teología agustiniana en respuesta a la doctrina de Pelagio y la controversia en razón de Lutero y la respuesta del Concilio de Trento (Auer, 1976: 314-318). Es importante tener en cuenta que Nicolás de Cusa es pre tridentino, no vive el segundo período que marcó significativamente la teología de la gracia, pero esto no quiere decir que sus aportes no sean significativos sobre todo por el hecho que uno de los tópicos con que se intenta actualmente renovar la teología de la gracia es a través de la teología mística, ya que, a partir de ella, es posible comprender la gracia en clave trinitaria, de filiación y de divinización, lo que permite hacer el nexo necesario entre la dogmática y la mística (García, 2006: 520).

De modo que realizar una aproximación a la gracia desde la obra $D e$ visione $D e i^{2}$, parece interesante puesto que los estudiosos consideran este escrito como la obra más mística del Cardenal (Beierwaltes, 2005: 89127), ya que tiene fuertes influencias, entre otras, de la Mística teológica de Dionisio Areopagita (Ludueña, 2005: 109-139; Hubert, 2007: 425438) y ciertamente en el tema de la gracia es notable la influencia de San Agustín (Ruiz de la Peña, 1991: 281).

Concretamente en este artículo se presentarán los aportes más importantes y significativos que entrega Nicolás de Cusa al tratado de la gracia, específicamente en su obra De visione Dei. La investigación se articula en torno a una pregunta metódica, a saber: la gracia como posibilidad del encuentro entre Dios y el hombre. Específicamente, este escrito se ordenará en tres apartados: el primero tiene relación con algunas consideraciones preliminares al momento de acercarse al tema de la gracia en De visione Dei; en el segundo se expondrá la teología de la gracia propiamente tal y en el tercero se presentará un esbozo sistemático sobre el tema.

2 Obra escrita en el año 1453 a petición del Abad del convento benedictino de Tegernsee, Gaspar Aindorffer. Él consulta en una carta a Nicolás de Cusa, sobre algunos aspectos centrales de la teología mística, como lo son la disyuntiva entre la preponderancia del elemento afectivo o el cognoscitivo de cara al conocimiento de Dios. Para iluminar esta problemática Nicolás de Cusa le envía, junto al escrito, una pintura del rostro de Dios que parece mirar todo lo que lo circunda a través de una mirada que es inmutable, inabarcable, omnipresente y omniprovidente (González, 2007: 11-13). 


\section{Consideraciones a la teología de la gracia en De visione Dei}

Antes de iniciar el estudio sobre la gracia en De visione Dei, es preciso señalar que, al sumergirse en la lectura de la obra, se aprecia una gran dificultad ya que el concepto aparece sólo en seis oportunidades, una vez como gratia y cinco veces como gratie. Es importante acotar que cuatro de estas citas aparecen en los primeros números de la obra (Cusa, 2007: nn. 11 y 14) y el resto hacia el final, cuando se refiere a la Trinidad (Cusa, 2007, n. 79) y cuando habla de Cristo (Cusa, 2007: n. 88). Sin embargo, si se fija la atención en otros conceptos relacionados con el tema tales como: don, misericordia, providencia y bondad, entre otros ${ }^{3}$, se enriquece el contenido y es posible establecer una serie de tejidos conceptuales que iluminan la investigación.

Otro aspecto esencial a tener presente es que la obra tiene como telón de fondo la teología veterotestamentaria del rostro, en tanto encuentro visivo cara a cara entre Dios y el hombre. Debido a este arraigue en la teología veterotestamentaria es que los especialistas han sostenido que teológicamente De visione Dei se puede considerar como una pretensión del autor de tratar la teología del rostro y con ello la gracia, como aquella que posibilita el encuentro del hombre con el rostro de Dios que de suyo es inalcanzable (Beierwaltes, 2005: 211). De allí que todo lo que Nicolás de Cusa desarrolla sobre el tema de la gracia en $D e$ visione Dei está permeado por la pedagogía visiva del ícono que el cusano envía a los monjes junto con la obra, por lo que la gracia se articula desde el ver de Dios, en tanto cuanto Dios mira, pero además entrega la posibilidad al hombre de sentirse mirado y a la vez de mirar a Dios. Es

3 Hay conceptos en la obra que implícitamente poseen la idea de gracia como es el caso de la palabra don (dono, donis) que aparece seis veces. Además aparece el verbo dar (dono) que aparece bajo distintas formas verbales tales como das $(3 \mathrm{x})$, dones $(2 \mathrm{x})$ dabis, dederis $(2 \mathrm{x})$ donare $(1 \mathrm{x})$. Conteniendo la misma idea se encuentra presente el verbo ofrecer (offero) que aparece una vez al terminar la obra. La palabra misericordia (misericordia, misericordiae) aparece como misericordia $(3 \mathrm{x})$, como misericordiae $(2 \mathrm{x})$, misericors $(2 \mathrm{x})$ y misericorditer $(1 \mathrm{x})$ y el verbo miseror $(3 \mathrm{x})$. Por su parte el sustantivo providencia (providentia, providentiae) se encuentra presente en la obra como providentia (1x) y providentiam $(1 \mathrm{x})$. Como adjetivo, se encuentra como provisor $(2 \mathrm{x})$, siempre referido a la figura de Dios Padre. Otro concepto importante es la bondad de Dios, que aparece como sustantivo bonitas $(7 \mathrm{x})$, bonitatis $(1 \mathrm{x})$, bonitate $(1 \mathrm{x})$, bonitatem $(2 x)$ y bonitati $(1 \mathrm{x})$. Como adjetivo bonum $(4 \mathrm{x})$, bonus $(3 \mathrm{x})$, bona $(1 \mathrm{x})$, bone $(2 \mathrm{x})$. El verbo atraer (attraho), en tanto cuanto es Dios el que realiza esta acción, aparece como attraberet (2x), attrabitur $(1 \mathrm{x})$, atrabentia $(1 \mathrm{x})$, attraxit $(2 \mathrm{x})$, attrabit $(2 \mathrm{x})$ y attractus $(1 \mathrm{x})$. Muy unido a este se encuentra el verbo trabo que tiene el sentido de atraer pero más precisamente de arrastrar, llevarse consigo a la fuerza, incluso de seducir, aparece como trabe $(1 \mathrm{x})$, trahas $(1 \mathrm{x})$, trahis $(1 \mathrm{x})$, trahendi $(1 \mathrm{x})$, trahi $(1 \mathrm{x})$. 
por eso que Nicolás de Cusa tiene el mérito de que en pleno siglo XV recupera la teología del rostro y de este modo sitúa la gracia como condición de posibilidad para el encuentro de Dios con el hombre.

\section{Teología de la gracia en De visione Dei}

Este apartado se articula a partir de las seis citas referidas a la gracia en la obra, ordenadas en tres apartados: el primero que hace relación a los ojos de gracia del rostro divino; el segundo que presenta al hombre constituido por gracia y en tercer lugar el hombre que vive en la gracia divina.

\subsection{Ojos de gracia}

Nicolás de Cusa presenta su reflexión teológica a partir de la analogía del ícono, de modo que, al momento de referirse a la gracia de Dios, lo hace plásticamente desde la figura del rostro y de un Dios que es principalmente theos (Cusa, 2007: 5). La primera cita a profundizar sitúa la gracia en los ojos de Dios, al respecto el cusano señala:

Si no me miras con los ojos de la gracia, la culpa es mía, porque estoy separado de ti por aversión y conversión a otra cosa, a la que prefiero en vez de ti (Cusa, 2007: 14).

En esta cita, el Cardenal entrega una clave muy importante para comprender su doctrina sobre la gracia: la pedagogía visiva; es aquí donde el cusano establecerá el lugar del encuentro profundo con Dios. De allí se entiende que el Cardenal hable de su propia experiencia de lo que significa que Dios mire con ojos de gracia, sin embargo, es interesante apuntar que no se detiene en las dimensiones que tiene esta mirada, pero sí hace referencia a la opción que tiene el hombre de no acoger este ver gracioso por elegir otras cosas.

Ahora bien, cabe la pregunta de descubrir específicamente qué significan estos ojos de gracia, al respecto nos aventuramos a trabajar con la premisa de que cuando Nicolás de Cusa se refiere a estos elementos visivos está hablando de la gracia de Dios de un modo particular. Pero, por qué no aventurar que el mismo Nicolás de Cusa puede especificar cómo son los ojos de gracia de cada una de las personas divinas, caracterizando de este modo el ver gracioso del Padre, como también del Hijo y del Espíritu Santo. 


\subsubsection{Los ojos de gracia del Padre}

Con respecto al Padre, Nicolás de Cusa (2007: 49) subraya enfáticamente que ver es crear y que Dios crea todas las cosas viéndolas, por tanto, la creación de Dios también se enmarcaría dentro de la dinámica de la gracia, pues sin ella todo cesaría. Lo interesante es que el cusano desarrolla el tema de la creación, estableciendo la relación entre el binomio ver y crear y, a la vez, crear y ser, entonces, podríamos concluir que la mirada de Dios es aquella que comunica el ser a todas las cosas, de modo que está presente en ellas, pero sin ser ellas (González, 1995: 630).

A su vez, el Cardenal (2007: 27), destaca la relación paternal que Dios establece con sus hijos, el cual tiene la particularidad de que al mismo tiempo puede ver y amar a cada uno y, a la vez, a todos los hombres, de modo que se produce en un solo acto la acción sobre lo particular y lo universal. Es, por tanto, una mirada paternal, por lo que el encuentro de miradas se produce bajo este prisma, o sea, si hay un padre es porque también hay un hijo, en este caso muchos hijos, lo más notable es que ama a cada uno como si fuera el único. Del mismo modo, que en una muchedumbre un padre puede identificar particularmente a su hijo, de igual forma los ojos de gracia del Padre divino reconocen a cada uno de los hombres, por lo que la gracia está vinculada al amor singular de Dios a cada hombre. Finalmente, desde esta premisa de la visión paterna, Nicolás de Cusa (2007: 28) desprende otras características del amor del Padre que es la providencia, en cuanto consecuencia lógica del hecho que el Padre no sólo genera al hijo sino que también se preocupa de su cuidado, de allí que el cusano afirmará que esta visión paternal es también providencia (González, 1995: 629). Ahora bien si la visión es providencia, la providencia es gracia y si al mismo tiempo la mirada es paternal, la gracia tiene también esta característica.

\subsubsection{Los ojos de gracia del Hijo}

Continuando con la reflexión en torno a la comprensión de estos ojos de gracia divinos, hay que dar un paso más de la mano del mismo Cardenal, ya que él mismo entrega otra pista para que el hombre pueda ver concretamente el rostro del Padre, en esta oportunidad subraya la necesidad imperiosa de la gracia divina:

Veo, pues, por la benignidad de tu gracia, en ti, Jesús, hijo del hombre, al Hijo de Dios, y en ti, Hijo de Dios, veo al Padre (Cusa, 2007: 88). 
Si se revisa la estructura de la obra ${ }^{4}$, se puede apreciar que Nicolás de Cusa comienza hablando de las características del mirar de Dios y es en esta primera sección donde se encuentra uno de sus atributos, a saber, los ojos de gracia; luego en unidades más breves se referirá a la infinitud de Dios y a la Trinidad para, posteriormente, finalizar con Jesucristo. Es de hecho en este último conjunto donde el Cardenal acuña esta expresión citada, a mi parecer, a modo de confesión de fe y es más, es la última vez que aparece el término gracia en la obra, esto como una forma de señalar que la misión de la gracia de Dios es que el hombre haga la confesión de que en Jesús se puede ver el rostro de Dios. En este sentido, se puede apreciar que el cusano se inspira en la teología bíblica, ya que en el Evangelio de san Juan se destaca la estrecha relación que existe entre el Hijo y el Padre cuando en uno de sus pasajes se señala que quien ve al Hijo ve al Padre (Jn 14,9), aspecto que según Mateo no puede ser reconocido sino por la acción de la gracia de Dios en el hombre (Mt 16,16-17).

Así pues, la gracia no sólo es una cualidad divina en cuanto que Dios nos mira graciosamente, sino que estamos frente a una comunicación concreta de la gracia que es el Hijo. De esta manera, para Nicolás de Cusa (2007: 82), es Cristo quien posibilita el encuentro con el Padre y, a la vez, nos regala participar de la filiación divina por adopción. En palabras de San Pablo hemos sido constituidos co-herederos con Cristo (Rm 8,17), donde se nos han dado todo los tesoros y gracias de nuestro Padre, creándose un nuevo nexo filial entre lo humano y lo divino, lo que sólo es posible en el Hijo, ello por pura gratuidad del Padre que lo ha enviado a los hombres (Cusa, 2007: 12).

Junto con lo anterior, el cusano (2007: 40) destaca la participación de Cristo en la creación puesto que unido totalmente al Padre llama a todas las cosas para que existan. Además, se refiere a la redención como el don más precioso para el hombre, en tanto cuanto la salvación viene dada por el hecho que Jesucristo asume la naturaleza humana para que todos los hombres participen de la vida divina. De hecho hacia el final de la obra Nicolás de Cusa (2007: 106) proclama un verdadero kerigma donde hace tomar conciencia que los dones divinos son solamente alcanzables por el hombre por medio de la kenosis del Hijo (Miller, 1990: 86-98).

\footnotetext{
4 La obra se podría subdividir en cuatro grandes secciones: Sección A: La visión de Dios (capítulo IV-XII); Sección B: La infinitud de Dios (capítulo XIII-XVI); Sección C: La Trinidad (capítulo XVII-XVIII) y Sección D: Jesús (capítulo XIX-XXV).
} 


\subsubsection{El Espíritu Santo y la acción graciosa del ver}

En esta dinámica de indagar sobre los datos que aporta De visione Dei para ir configurando la presentación que propone Nicolás de Cusa en torno a la gracia increada, cabe preguntar sobre cuál sería el papel del Espíritu Santo. Pues hasta el momento la gracia ha sido relacionada principalmente con elementos de tipo visivo, como los ojos, la mirada y, por último, con el rostro por excelencia que es Cristo.

En primer lugar hay que señalar que el cusano va a insertar el tema del Espíritu Santo en un contexto trinitario ${ }^{5}$. Para el cusano el Espíritu constituirá el nexo entre el Padre [Dios amante] y el Hijo [Dios amable], de modo que la tercera persona de la Trinidad establece la unión de esta relación filial estrechísima. Para dar cuenta de esta unión el Cardenal (2007: 84) utiliza el binomio acto y concepto, con ello se refiere al Padre y al Hijo respectivamente, del cual procede el Espíritu Santo; de la misma forma utiliza la imagen del amor, en el sentido que lo que une al amante con el amable es el amar y este último es el papel del Espíritu Santo.

Nicolás de Cusa no sólo se limita a atribuirle al Espíritu Santo la misión de la unión o del nexo, la cual sería una explicitación de la relación intratrinitraria, sino que además le otorgará otra característica ad extra de la Trinidad, para lo cual recurrirá a otras imágenes como el motor inmóvil que correspondería a la figura del Padre y del móvil que simbolizaría al Hijo, donde al Espíritu no se asemejará ni con lo uno ni con lo otro, sino que le corresponderá el lugar del movimiento. Esta simbólica del movimiento es relacionada con un concepto técnico que articula el pensamiento de Nicolás de Cusa (2007: 84), cual es el de la explicatio, atribuyéndole al Espíritu Santo esta función en orden a todas las cosas, o sea, es el Espíritu Santo quien hace posible que se manifiesten todas las cosas, se revelen o se expresen mientras que al Verbo le atribuye el hecho que estén concebidas en Él, lo que el Cardenal (2007: 43) denominará técnicamente la complicatio en el Verbo ${ }^{6}$.

Desde esta concepción del Espíritu Santo, es decir, como movimiento se puede vislumbrar alguna respuesta sobre lo que se planteó al inicio de este apartado, a saber, de qué manera el Espíritu Santo aparece en el icono. Al respecto, es posible señalar que no lo hace como rostro sino que va apareciendo como aquel que posibilita que estos ojos de gracia puedan mirar, es decir, si los ojos son la visión complicada,

\footnotetext{
5 Ganoczy (2005: 127-159) va a valorar el aporte que entrega Nicolás de Cusa al tema de la Trinidad.

6 Con respecto a la complicatio y explicatio en De visione Dei, véase Beierwaltes (2005: 185-186).
} 
la explicatio de esa mirada es factible por el Espíritu Santo. Entendida así la misión del Espíritu, se puede decir que es él quien permite que el ser humano reciba tan magníficos dones de parte del Padre y del Hijo, siendo el posibilitador para que los ojos de gracia puedan desarrollar realmente la acción de ver por parte del Dios y al mismo tiempo de que el hombre pueda ver a Dios.

Además, precisa Nicolás de Cusa (2007: 92), es el Espíritu Santo quien permite la unión de dos sujetos infinitamente distintos. Para esto alude a la imagen paulina del hombre nuevo y del hombre viejo (Ef 4, 22-24), con ello señala que ahora en Cristo el hombre puede adquirir una nueva dimensión espiritual, en la medida que se une a Cristo y se derrama en él el Espíritu Santo ( $R m$ 8, 9), de modo que de ninguna manera se vincula esencialmente a la naturaleza divina, pero sí se puede acceder a ella por medio del espíritu y de esa forma alcanzar el paraíso, que es el encuentro definitivo con Dios en la visión beatífica.

\subsection{E1 hombre constituido por gracia}

Cuando el cusano se refiere a la gracia de Dios como la mirada de éste al hombre, tiene de fondo toda la historia de salvación que Dios ha llevado adelante a favor de la redención humana, cuyo culmen es la visión beatífica. De modo que, si la gracia está en esta perspectiva salvífica y escatológica, tiene sentido preguntarse por el sujeto a quien se dirigen estos dones de Dios. En el fondo se trata de acercarnos a la antropología que está presente en De visione Dei siempre en vistas a la comprensión de la gracia, es por este motivo que parece oportuno partir con una convicción existencial que expresa Nicolás de Cusa con respecto de sí mismo y su experiencia humana de haber sido invadido por la gracia de Dios:

Me has dado el ser, Señor, y un ser tal que puede hacerse continuamente más capaz de tu gracia y de tu bondad. Y esta fuerza, que yo obtengo de ti y en la que poseo la viva imagen de la fuerza de tu omnipotencia, es la voluntad libre, mediante la cual puedo ampliar o restringir la capacidad de recibir tu gracia (Cusa, 2007: 12).

Es interesante que en esta breve cita, donde aparece en dos oportunidades el concepto de gracia, se puede descubrir en primer lugar la relación que se establece entre creador y creatura a la luz de la providencia divina entorno al don del ser, que Nicolás de Cusa (2007: 40) lo ilustra plásticamente con el ícono que constantemente está mirando al hombre porque si lo dejara de ver dejaría de existir. Por otra parte, en el 
hecho que el Cardenal (2007: 109) se reconozca como creatura, es posible descubrir en otras partes de la obra cómo subyace en la antropología del cusano los textos del Génesis 1 y 2, donde principalmente va a colocar el acento en que el hombre ha sido constituido como imagen y semejanza de Dios. A la vez, el cusano (2007: 10), subrayará la condición de libertad del ser humano que es donde se juega el hecho de recibir o rechazar la gracia de Dios, de modo que la libertad aparece como una condición fundamental del hombre que lo hace estar en un constante combate de abrirse o cerrarse a la gracia de Dios.

Junto con lo anterior es interesante señalar que Nicolás de Cusa (2007: 118) presenta la condición de imagen y semejanza como una tarea a realizar pues la imagen por excelencia es el Hijo. De este modo el cusano nos abre un camino por medio de Jesucristo, y es al hombre al cual le compete en su libertad irse perfeccionando en torno a esta imagen del Padre que es Cristo, por lo tanto, la condición de imagen y semejanza en el ser humano no es estática sino dinámica, es por eso que se señala que el hombre puede alcanzar distintos grados de perfección que lo van configurando a semejanza del Hijo.

Es en este sentido que el cusano (2007: 27) presenta el clásico binomio gracia y libertad, enfatizando principalmente la libertad, pero sin dejar de lado la gracia preeminente que presenta en la obra bajo la categoría del deseo. Este concepto, el Cardenal (2007: 73) lo considera como propio del hombre, pero es necesario consignar que ha sido dado por Dios para llevarlo a Dios, o sea, bajo la nominación de deseo podríamos entender mejor el tema de gracia y naturaleza pues el cusano afirmará que es Dios mismo quien conduce al hombre hacia Él ${ }^{7}$. Esto porque en su lógica el ser humano encuentra su plenitud sólo en Dios, por tanto no habría lesiones a temas como la autonomía o el empequeñecimiento de la dignidad humana debido a su ligación con la divinidad (Dupré, 1990: 153-170).

Otro aspecto que es muy importante a la hora de revisar el tema de la gracia en De visione Dei es que el hombre posee la cualidad de ser capaz de recibir esta gracia $^{8}$, en el sentido que ya ontológicamente el ser humano presenta una apertura a Dios debido a la impronta que éste ha dejado en el ser creado. Pero además él sería capaz de alcanzar atributos

\footnotetext{
7 Con respecto al tema del deseo en Nicolás de Cusa, Von Balthasar (1988: 213) señala algunas fuentes del desarrollo de este pensamiento del cusano en Aristóteles, Gregorio Magno y Gregorio de Nisa.

8 En tres citas de las seis que hay sobre la gracia encontramos esta idea del hombre que es capaz de recibir la gracia de Dios (Cusa, 2007: 12 (2x); 15).
} 
divinos tales como la bondad y la verdad, sin embargo, para que esto se realice es necesario que el hombre lo haga a través de la voluntad libre la cual le ayuda para ensanchar o circunscribir la gracia de Dios (André, 2005: 19). Para Nicolás de Cusa (2007: 11) se trata, por tanto, que desde Dios todos estos atributos se presentan en su grado máximo más allá de toda concepción humana; y por su parte desde el hombre, le compete dar lo mejor de sí en toda su libertad para así aspirar a los bienes superiores que solamente puede alcanzar quien experimenta el amor de Dios. De allí que el cusano sitúa la gracia y la libertad en la dimensión del amor, donde el hombre puede amar a Dios por el hecho que Dios es el amor por antonomasia, y de ese modo puede encausar su libertad hacia la aceptación de la gracia de Dios. Esta forma de concebir la relación gracia y libertad tiene de fondo el binomio "complicatio-explicatio", utilizado por el Cardenal (2001: libro II), en tanto cuanto los atributos del Absoluto están contraídas en la esencia del ser humano y explicadas, a su vez, en el ser singular.

En esta perspectiva, el cusano no ignora la condición de fragilidad en el ser humano, de hecho va a presentar el pecado utilizando como telón de fondo la perícopa bíblica del Hijo pródigo (Lc 15, 11-24). Así pues, según el Cardenal (2007: 28), el negar a Dios como Padre conlleva a rechazar nuestra relación filial negando además, todos los dones recibidos como verdaderos hijos en el Hijo y la consecuencia de esto es que la condición del hombre llega a ser aún peor, pues se priva del don del ejercicio de la libertad en cuanto dueño de sí mismo. Entonces, la situación es deplorable ya que esta libertad se convierte en esclavitud ya que es sometida al príncipe de este mundo ( $\mathrm{Hb} \mathrm{2,14-15).} \mathrm{Por} \mathrm{tanto,} \mathrm{las}$ circunstancias existenciales del hombre pecador están lejos de constituirse en una vida feliz, sin embargo, Dios no se deja de comunicar con el hombre advirtiéndonos de nuestra situación de pecado que a la postre se constituye en una negación de lo que somos, de allí que el Cardenal señale bajo su vivencia de fe que:

Y sin embargo tú no te separas absolutamente de mí, sino que tu misericordia me sigue, por si acaso yo quisiera en algún momento volverme hacia ti, para ser capaz de tu gracia (Cusa, 2007: 15).

Para Nicolás de Cusa el hombre que abandona a Dios se constituye en pecador (Jer 13,10), pero al mismo tiempo que el hombre puede realizar este movimiento de apartarse de Dios, existe otro de retorno, sin embargo, lo más originario está en el actuar de Dios ya que él va por delante, de modo que antes que el hombre vuelva a fijar su mirada ya Dios la posa sobre él, de allí que el cusano indique que la mirada es 
misericordiosa porque si bien es cierto hay una disposición del hombre a la conversión, el actuar de Dios ha sido previo.

Así pues, Dios está constantemente de cara a nosotros y quiere nuestra conversión, con el único propósito que seamos felices, es por eso que nos sigue con su mirada, sin embargo, esto no es más que una analogía del hecho que realmente Dios vive en cada hombre de modo que esta figura de que Dios está continuamente tras el hombre, es una exteriorización de una realidad profundamente interna anidada en el ser más íntimo de la persona (Cusa, 2001b: cap.13).

Finalmente no se puede dejar de señalar que junto con subrayar el hecho que el hombre en su libertad es capaz de la gracia de Dios, también Nicolás de Cusa (2007: 26) afirmará que el ser humano además tiene la facultad de ser capaz de ser sí mismo, o sea, capaz de autoposeerse y sólo así podrá entrar en comunión con Dios, por lo tanto, podría señalar que el camino es desde el hombre hacia Dios. Este acento antropológico por el que apuesta el cusano (2007: 25) trae como consecuencia el hecho que se le dé mucha importancia al encuentro del ser consigo mismo, y así aparece potentemente que la gracia supone la naturaleza, y si la supone, no hay nada mejor que ser tremendamente consciente de mi yo para que de ese modo Dios actúe, perfeccionando así mi ser.

\subsection{E1 hombre que vive en gracia}

En este último apartado se presentará al hombre agraciado, es decir, cómo Nicolás de Cusa muestra las consecuencias de la aceptación de la gracia de Dios. Para ello se utilizará otra cita clave a la hora de comprender la gracia en De visione Dei:

Me basta tu gracia, con la que me haces estar cierto de que tú eres incomprehensible, y por la que me elevas a la firme esperanza de que llegaré, bajo tu guía, a la fruición de ti (Cusa, 2007: 79).

Para comprender mejor esta bellísima expresión del cusano, es importante consignar que previamente ha presentado a San Pablo como aquél que tuvo el privilegio de que el Señor lo arrebatara al paraíso, el cual es el único lugar donde propiamente se puede ver a Dios ${ }^{9}$. En este sentido, Nicolás de Cusa (2007: 52) acuña un lenguaje propio para dar cuenta del misterio de Dios, en tanto cuanto el hombre se encuentra al

\footnotetext{
9 Nicolás de Cusa (2001c: 2) va a retomar esta misma imagen de San Pablo en su obra De apice theoriae.
} 
otro lado del muro donde no puede acceder al paraíso, sino que a lo más puede ver algo del rostro de Dios en las criaturas y en sí mismo y, de ese modo, gozarse en la providencia divina, pero está lejos de unirse a él.

A su vez, el cusano atestigua que él no ha tenido esa experiencia de haber sido arrebatado al paraíso, la cual comparte con el resto de los hombres, entonces el problema está en cómo llegar al paraíso y de esa forma poder encontrarse realmente con Dios. Y es, en este contexto, cuando afirma con vehemencia que le basta la gracia de Dios para encontrarse con él. Es por eso que el Cardenal se manifiesta eternamente agradecido a Dios porque es a través de Él que se puede elevar y entrar en su misterio, diciendo: Et sufficit mibi gratia tua.

A partir de esta cita desprendemos tres aspecto que son muy importantes a la hora de comprender la importancia de la gracia en cuanto posibilitadora del encuentro entre Dios y el hombre ya que, si bien en el inicio del artículo, hemos posado nuestros ojos en el rostro de Dios, ahora es el momento de mirarnos a nosotros mismos desde la transformación que ha obrado aquél que providencialmente no nos deja de mirar.

El primer aspecto tiene que ver con el hecho que la gracia nos da la posibilidad de comprender lo incomprensible. De hecho Nicolás de Cusa (2007: 69) frente al conocimiento de Dios presenta una paradoja, en el sentido que comprendo que no comprendo y más comprendo, ¿cómo se entiende esto? No es otra cosa que el misterio de la grandeza de Dios donde es necesario precisar que si bien puedo conocerle a través de las criaturas y a través del encuentro conmigo mismo, no llego a alcanzar lo que propiamente es Dios pues sólo puedo acercarme a su imagen lo cual resulta insuficiente para captar su verdad absoluta (González, 1995: 638).

He aquí el hecho por el cual Dios es incomprensible, pero al mismo tiempo, es lo que sacia la plenitud del deseo en el hombre. Es por este motivo, que podemos concluir que la incomprensibilidad de Dios aparece en forma positiva en el pensamiento del cusano pues, asumiendo la realidad del cognoscente finito es lo que me posibilita comprender ${ }^{10}$. Nicolás de Cusa parte de la premisa que el intelecto no puede captar la infinitud porque hacerlo sería conocer aquello que de suyo no se puede conocer, como tampoco se puede ver ni tener acceso a él ${ }^{11}$. Este presupuesto es fundamental, pues el hombre necesita reconocer en

10 Este modo de entender lo incomprensible en Dios tiene su fuente en Dionisio Areopagita (2007: Epístola I).

11 En este sentido, comenta el profesor Beierwaltes (2005: 89-102), Nicolás de Cusa es heredero del neoplatonismo quienes sostenían que el primer principio de todo ente es incomprensible e inefable en su esencia. 
primer lugar su pequeñez si quiere contemplar en algo este misterio ${ }^{12}$. Este reconocimiento es para el Cardenal el inicio de la sabiduría, de allí que lo llame docta ignorantia ${ }^{13}$ la cual tiene como lugar propio la tiniebla o la sombra (Cusa, 2007: 52).

El segundo aspecto tiene que ver con el hecho que Dios nos regala la gracia de la guía divina para conducirnos al encuentro de Dios. En este sentido, para Nicolás de Cusa (2007: 90) Jesús aparece como el verdadero maestro para todos los hombres, ya que sólo él tiene la posibilidad real de mostrar la verdad de $\operatorname{Dios}^{14}$. Es por eso que se afirma que Jesús es el camino, o sea la sublime guía, de modo que el hombre al entrar en la verdad profunda de su existencia a la luz de Cristo, pueda alcanzar la verdad absoluta, la alegría y la vida en plenitud (Jn 14, 6). Por su parte, es necesario precisar que toda la misión de Cristo está en razón del Padre pues Jesús es la plena revelación del Padre dada gratuitamente a los hombres.

Además Nicolás de Cusa (2007: 91) subrayará la importancia de las Escrituras en razón que en ellas encontramos una guía concreta que nos conduce al encuentro con Cristo. Se trata de un verdadero alimento del cual hay que nutrirse, principalmente de los Evangelio, y para iluminar mejor la necesidad que el cristiano tiene de las Escrituras, el cusano va a utilizar la imagen bíblica del maná (Ex 16,31; Jn 6,31-35), en cuanto que la palabra divina sacia totalmente al hombre y colma totalmente sus deseos más profundo. Ahora bien, esta Palabra de vida, para el Cardenal (2007: 109), no es solamente escritura, cuyos caracteres nos quieren dar un mensaje, sino que lo que le da fuerza salvífica a este anuncio es el testimonio de Jesucristo que ha dado la vida por la humanidad.

Por último, el tercer elemento que regala la gracia al hombre, es la posibilidad de responder a la invitación divina de la gloria definitiva. De hecho al ser humano le basta la gracia de Dios para recibir sus dones,

$12 \mathrm{Al}$ respecto, João Maria André comenta que la docta ignorantia es para el cusano una expresión que refleja nuestra condición antropológica ante el ser y la verdad (André, 2005: 17).

13 El cusano tratará ampliamente este asunto en su obra más conocida De docta ignorancia, en la cual señala: «En este primer libro intentaré inquirir incomprensiblemente por encima de la razón humana este máximo, en el que se cree por la fe de modo indudable como Dios de todas las naciones, con la guía de aquel que sólo habita la luz inaccesible» (Cusa, 1984: L. I, cap. 2).

$14 \mathrm{Al}$ respecto, el cusano afirma: «Bendito sea Dios que nos redimió con su Hijo de las tinieblas de tan grande ignorancia, para que sepamos que es falso y engañoso todo mediador que no sea Cristo, el cual es la Verdad, y todo lo que sea hecho con una fe que no sea la de Jesús. Pues no hay más que un Jesús Señor Nuestro, poderoso por encima de todo, que nos colma con toda bendición, y el único que desborda nuestros defectos y los suple» (Cusa, 1984: L. III, cap. XI). 
como son la vida, la felicidad plena, la inmortalidad, la gloria y el Reino. Todo esto, porque hemos sido constituidos co-herederos con Cristo (Gal 4,7), ya que en él se nos ha dado todo los tesoros y gracias de nuestro Padre, creándose un nuevo nexo filial entre lo humano y lo divino, que sólo es posible en el Hijo por pura gratuidad del Padre. Es así como el Cardenal (2007: 12) compara la aeternae felicitatis con un jardín donde son satisfechos todos los deseos e incluso más, llega a decir que ni siquiera es comparable con lo que el hombre conoce, ni menos se puede encontrar presente en aquello que existe.

Para el cusano (2007: 93), en el ver a Dios radica la felicidad del hombre y la salvación y sólo a través de Jesucristo se accede a la fruición de Dios y se produce el milagro de la unión entre el infinito y el finito ${ }^{15}$. Sin embargo, esta unión de espíritus no se produce tan sólo de un modo individual sino también como comunidad eclesial, abriéndonos así a la comunión de espíritus. Aquí a aparece el misterio de la Iglesia como lugar de encuentro de aquellos que se quieren encontrar con Cristo, de modo que la experiencia de cada uno nutre la propia y eso me enriquece aún más como persona. Es así como, para el Cardenal (2007: 117), el individuo que vive en la gracia de Dios, necesariamente tiene que ser un hombre que vive y participa de la comunidad pues sólo así se ayuda a la perseverancia en este peregrinar que lleva al encuentro definitivo con Dios.

Por último, no podemos dejar de mencionar el hecho que la gracia dona la esperanza que Dios regala junto a la fe y la caridad, en cuyo caso todo carecería de sentido si el hombre no tuviese la esperanza en Aquel que le promete la vida en plenitud ${ }^{16}$. Al mismo tiempo, la esperanza es ya la posesión de todos los dones que el hombre puede obtener por gracia y cuya plenitud la obtendrá en la visión beatífica porque lo imposible metafísicamente entre el infinito y lo finito se hace posible sólo por la gracia.

15 Al respecto, el cusano siempre salvaguarda la diferencia de constitución óntica entre Dios y el hombre: «Todos aquellos que se unen a Cristo, bien en esta vida por la fe y la caridad, bien en la otra por comprensión y la fruición, como queda una diferencia gradual, se unen de modo que no pueden unirse más, permaneciendo aquella diferencia, de forma que sin tal unión ninguno subsiste y por la unión ninguno sale de su grado» (Cusa, 1984: L. III, cap. XII).

16 Con respecto a la esperanza el cusano afirma: «Y no puede haber una fe grande sin la santa esperanza de la fruición del propio Jesús. Pues, ¿cómo podría nadie tener una fe cierta si no esperara la promesa que Cristo le ha hecho?»(Cusa, 1984: L. III, cap. XI). 


\section{Esbozo sistemático de la gracia}

En este apartado se realizará un esbozo sistemático sobre la gracia en Nicolás de Cusa. Para llevar adelante este propósito, se debe precisar que todo lo que se diga de la gracia, en este contexto, está permeado por la pedagogía visiva del ícono que el cusano desarrolla en la obra. Es por esto que el acento teológico en la forma de tratar el tema de la gracia se articula desde el ver de Dios, por lo que la mirada divina para el cusano se podría entender propiamente como gracia.

Ahora bien, bajo esta premisa vemos adecuado presentar este esbozo haciéndonos cargo de nuestra hipótesis en cuanto que la gracia es condición de posibilidad para el encuentro de Dios con el hombre, y lo es en orden a tres dimensiones: ontológica, gnoseológica y escatológica.

Desde el ámbito ontológico se puede señalar que Nicolás de Cusa sitúa la gracia desde el momento mismo de la creación y por ende, de la existencia de cada uno de los sujetos. Al mismo tiempo, fue posible apreciar que el acto creacional no es estático en cuanto a que se resume a un espacio puntual de tiempo, sino que es dinámico y es por eso que la gracia tiene la característica de ser providente, pues la mirada divina siempre va acompañando al hombre durante su vida, de lo contrario éste no existiría.

Entonces, se constata, en el pensamiento del cusano, que la gracia divina está presente desde el origen de cada persona y aún más, cada hombre ha sido constituido como imagen y semejanza de Dios, lo cual hace que el sujeto perciba una huella divina que se expresa a través del deseo de Dios. De esta forma, naturalmente, al ser humano le ha sido otorgada la cualidad de ser capax Dei, de allí que la posibilidad del encuentro entre Dios y el hombre está sellada en el hombre mismo, desde la constitución ontológica que es un don gratuito de Dios.

Sin embargo, esta constitución natural del hombre no es un determinismo, ya que se trata de un deseo que está abierto a Dios pero requiere de la adhesión de la libertad, en cuanto a aceptar o rechazar la gracia. Es aquí donde nos encontramos con la fragilidad humana como una condición propia del hombre que lo hace estar en un constante combate en cuanto a alejarse de Dios, es a esto a lo que el cusano denomina pecado, en cuanto a farrearse la posibilidad de gustar los dones ofrecidos por Dios.

Por su parte, si la constitución propia del hombre creado por Dios permite el encuentro, el acontecimiento de la encarnación va a inaugurar una nueva forma de relación entre Dios y el hombre, puesto que nos va regalar la opción de participar de la filiación, es decir, nos posibilita una relación no solamente con un Dios creador, que ya es bastante, sino que 
además nos abre a la relación con un Padre que ha sido manifestado por el Hijo.

En este sentido, la encarnación aparece como la máxima acción divina a favor de los hombres y es por ello que constituye a Jesús en la imagen auténtica de la gracia de Dios. Por lo tanto, en Cristo podemos ver cómo se va posibilitando el encuentro entre Dios y el hombre, sobre todo por el hecho que si bien la encarnación no cambia nuestra constitución ontológica de seres humanos, sí posibilita la deificación de la naturaleza humana. Es así como Jesucristo participa del acto creador junto al Padre y, a través del acontecimiento pascual, inaugura una nueva creación, abriendo al ser humano la posibilidad de la resurrección y la vida eterna, haciéndolo partícipe de su mismo espíritu. De modo que la experiencia de la gracia posibilita que cada hombre sea transformado en el hombre nuevo redimido por Cristo.

En conclusión, ya desde la constitución ontológica del hombre podemos subrayar la cooperación de la gracia divina en el encuentro que éste tiene con Dios, que incluso permite un acercamiento tal que llega hasta la filiación.

Podemos continuar revisando nuestra hipótesis de trabajo ahora desde el punto de vista gnoseológico, o sea, ver hasta qué punto la gracia me permite conocer a Dios. Una de las pistas que nos da, en este sentido, el cusano en De visione Dei es que explícitamente señala que Dios mira al hombre con ojos de gracia, pero no sólo eso, sino que a través del Espíritu Santo que es nexo y movimiento, permite que el hombre pueda mirar a Dios. Esto ya nos abre una nueva perspectiva, que no es menor, puesto que de propio Dios no se puede ver.

Ahora bien, ciertamente el sólo hecho de ver a Dios permite conocerle, pero Nicolás de Cusa va más allá cuando señala que es la gracia la que permite comprender lo incomprensible. De este modo, el encuentro entre Dios y el hombre se debe dar necesariamente a través de la gracia, la cual permite entrar en la divina tiniebla y, desde allí, empezar a atisbar la luz de modo de poder comprender lo incomprensible. En este sentido, en el lenguaje del cusano, se sostiene que para alcanzar a Dios desde el conocimiento es necesario adentrarse en la docta ignorancia, es decir, se parte de la premisa que no se sabe nada para, de ese modo, recibir la gracia de acercarse en algo al misterio de Dios. Esta proximidad puede ser cada vez mayor en la medida que el hombre en su libertad se abra a la guía divina y, en este sentido, el camino por excelencia es Cristo de modo que es necesario su seguimiento a través de la escucha de su palabra, siempre unido a los testigos de la Buena Noticia, que es la comunidad eclesial. 
Para terminar esta dimensión gnoseológica, podemos señalar que el conocer a Dios es imposible sin la iniciativa divina, por tanto, la única posibilidad que le queda al hombre para el encuentro con Dios en este plano es la gracia de Dios, en el sentido que éste se ha mostrado a través de la creación, se ha comunicado a los hombres de distintas maneras y finalmente lo ha hecho en plenitud en Jesucristo.

Ahora bien, toda esta historia de salvación que Dios ha llevado adelante a favor de la humanidad, tiene su culmen en la visión beatífica, de modo que la gracia de Dios derramada sobreabundantemente, tiene una connotación escatológica que nos lleva a la gloria definitiva pero sin dejar de gustar estos dones eternos ya en la propia existencia actual.

Por su parte, el que nos abre el camino hacia la definitiva visión de Dios es Cristo quien nos hace coherederos de los bienes del Padre, por tanto sólo a través de la participación en la filiación, podemos gustar de todos los dones del Hijo en su gloria. Esto, para Nicolás de Cusa, constituye la máxima felicidad humana, por tanto la gracia conducente a la gloria, podemos entenderla como una pedagogía que va construyendo la felicidad definitiva en la esperanza.

De este modo, el encuentro entre Dios y el hombre queda posibilitado por la gracia, incluso más allá de nuestros límites espaciales y temporales, por tanto se trata de una invitación totalmente gratuita a la gloria de Dios y de esa manera, el hombre tiene la posibilidad de ver a Dios no sólo a través de una experiencia mística como la de San Pablo, que fue arrebatado al tercer cielo, sino que cada hombre y mujer de fe pueden ver a Dios a partir de la gracia que les permite entrar en la vida eterna.

\section{Conclusión}

A partir de la lectura de De visione Dei, podemos vislumbrar los aportes que entrega Nicolás de Cusa de cara a la teología de la gracia ya que él va a insistir en temas como la creación y la escatología, realidades que entiende como un proceso en que la creatura va hacia lo infinito, lo cual enmarca a nuestro autor en una dinámica donde se pone el acento en la gracia increada pero sin dejar de lado el giro antropológico en cuanto a la gracia creada y de esa manera, comprender al hombre como un ser agraciado. En este sentido, el cusano va a colocar el acento en el 
amor gratuito de Dios y no en primer lugar en la liberación del pecado, el cual va a aparecer como aquello que imposibilita el encuentro con Dios ${ }^{17}$.

Otra dimensión que resulta interesante es que estamos frente a una obra donde están estrechamente unidas el tema de la gracia y la gloria, en el sentido que la comprensión de la visión definitiva de Dios en la eternidad nos posibilita la comprensión del encuentro categorial que es posible que se dé entre Dios y el hombre ${ }^{18}$.

Por otra parte, es atractivo el hecho que en De visione Dei, Nicolás de Cusa va a unir la teología de la gracia, al rostro y a la mirada divina, realizando a través de estas imágenes una analogía tal que le permite dar cuenta de complejos temas teológicos tales como la creación, la Trinidad, Jesucristo y otros. De modo que desde la mirada del infinito podemos comprender nuestra infinitud, y es en este sentido que puede ser interesante su aporte ya que hay posturas que sostienen que para una renovación de la teología de la gracia necesariamente debemos partir desde Dios y no desde el hombre en su orientación hacia Dios, sino que más bien se trata de partir desde la plenitud de la vida trinitaria y cómo esta vida divina es entregada al hombre a través de la encarnación del Verbo y santificación por el Espíritu Santo (García, 2006: 509) ${ }^{19}$. Para lo cual el cusano utiliza un lenguaje propio a través de imágenes y conceptos como el muro de la coincidencia de los opuestos, la complicatio y la explicatio, la docta ignorancia, entre otros, lo cual podría ayudar a la explicitación de la doctrina de la gracia en la teología contemporánea.

Al mismo tiempo, el hecho que la obra sitúe al lector ante el icono de Dios, es decir ante su rostro y sus ojos, le da al escrito una impronta personal de encuentro amoroso capaz de realizarse en la paradoja del misterio del infinito y el finito. En este sentido, uno de los intentos de renovación, pasa por situar el tema de la gracia en la paradoja primordial entre el ser infinito y el finito, en donde la gracia también está circunscrita a esta paradoja, pues en la realidad de la gracia se dan cita Dios y el hombre en tanto Dios encarnado (Deus capax homini) y del

\footnotetext{
17 Javier Prades sostiene que la renovación de la teología de la gracia debiera darse en la acentuación del perdón y de la salvación en tanto experiencia de la gratuidad por encima del acecho del mal y del pecado, ya que el misterio de la iniquidad ha sido vencida en virtud de la redención de Cristo (García, 2006: 502-503).

18 Al respecto, K. Rahner (1989: 149) señala en el Curso fundamental sobre la fe, la importancia de unir gracia y visión en orden a comprender de mejor manera la doctrina de la visión inmediata de Dios.

19 En esta línea se encontraría, por ejemplo, Urs von Balthasar, quien pone el acento en el «más» desbordante del amor eterno entre el Padre, el Hijo y el Espíritu Santo, donde en este último adquiere rostro propio. De ahí que la pneumatología se vaya constituyendo en principio estructurante del tratado De gratia (Meis, 1990: 231-232).
} 
hombre en su deseo innato de divinización (bomo capax Dei). A partir de esta premisa se propone comprender la gracia desde dos paradojas: una en cuanto que la gracia se experimenta en el mundo entre la aparente inutilidad y su admirable fecundidad, y por otro, entre la verticalidad de su origen y la horizontalidad de su destino (García 2006: 503-505).

Además, el tono de la obra, donde muchas veces el cusano eleva verdaderas súplicas a Dios o bien le alaba en su grandeza, le da el carácter de ser un escrito muy vivo donde la gracia aparece como una verdadera experiencia vital del hombre, donde especialmente el ser humano está llamado a gozarse en los dones de Dios y por tanto a sentirse agradecido de su amor. En este sentido los intentos de renovación de la teología de la gracia pasan por entenderla como lo que es bueno para otro, de modo que intrínsecamente en la gracia hay un proceso propio de bondad dada por Dios, ya que Él es por excelencia el sumo Bien, y a la vez es el Amor sublime, donde las tres personas divinas se entregan la una a la otra. De modo que la gracia increada es bondad y alteridad, donde hay entrega y encuentro personal, vida, acción y comunión (Bazarra, 1998: 140-141).

\section{REFERENCIAS}

-André, J. M. (2005). Conocer es dialogar. La metáfora del conocimiento y su dimensión dialógica en el pensamiento de Nicolás de Cusa. En J. Machetta \& C. D'amico (Eds.), El problema del conocimiento en Nicolás de Cusa: genealogía y proyección (págs. 15-38). Buenos Aires: Biblos.

-Areopagita, D. (2007). Epístolas I. En D. Areopagita, Obras completas (H. Cid Blanco, Trad.). Madrid: Biblioteca de Autores Cristianos.

-Auer, J. (1976). Historia de la doctrina de la gracia. En Sacramentum Mundi. (Segunda edición, Vol. III, págs. 314-318). Barcelona: Herder.

-Balthasar, U. von (1988). El Nudo. Nicolás de Cusa. En U. von Balthasar, Gloria. (E. Saura, Trad., Vol. 5, págs. 195-232). Madrid: Ediciones Encuentro.

-Bazarra, C. (1998). Reflexión inicial sobre la gracia. En Naturaleza y Gracia, vol. XLV, 139-150.

-Beirwaltes, W (2005). Cusanus. Reflexión metafísica y espiritualidad. Pamplona: EUNSA.

-Cabrié, A. (2005). Una aproximación al tema de la gracia en los documentos del Concilio Vaticano II. Veritas (13), 149-171.

-Cusa, N. de (1984). De docta ignorantia. (M. Fuentes Benot, Trad.). Buenos Aires: Orbis.

-Cusa, N. de (1994). La visión de Dios (A. L. González, Trad.) Pamplona: EUNSA. 
-Cusa, N. de (2000): Opera omnia. De visione Dei. Hamburgi: Adelaida Dorothea Riemann.

-Cusa, N. de (2005). De non aliud (A. L. González, Trad.). Cuadernos de Anuario Filosófico, (180), 5-76.

-Cusa, N. de (2001). Idiota de sapentia. (A. L. González, Trad.). Pamplona: EUNSA.

-Cusa, N. de (2001). Idiota de mente. (A. L. González, Trad.). Pamplona: EUNSA.

-Cusa, N. de (2001). De apice theoriae. (A. L. González, Trad.). Pamplona: EUNSA.

-Dupré, L. (1990). Nature and Grace in Nicholas of Cusa's Mystical Philosophy. American Catholic Philosophical Quarterly, LXIV, 153-170.

-Ganoczy, A. (2005). La trinidad creadora. (F. Torres, Trad.). Salamanca: Secretariado trinitario.

-García, C. (2006). Una mirada a la gracia: nota bibliográfica. Burgense (47), 501520.

-González, A. L. (1994). Introducción. En N. de Cusa: La visión de Dios (A. L. González, Trad.) Pamplona: EUNSA.

-González, A. L. (1995). Ver e imagen del ver acotaciones sobre el capítulo XV del De visione Dei de Nicolás de Cusa. Anuario Filosófico (28), 627-648.

-González, A. L. (2001). Nicolás de Cusa. Sinópsis de su vida y obra. En N. de Cusa, Diálogos del Idiota. El Possest. La cumbre de la teoría (A. L. González, Trad., págs. 11-14). Pamplona: EUNSA.

-Hubert, A. (2007). Influencia del Pseudo-Dionisio en Nicolás de Cusa. Teología y Vida 48, 425-438.

-Ludueña, E. (2005). Teología mística y cristología. El Pseudo-Dionisio y Nicolás de Cusa. En J. Machetta \& C. D’amico (Eds.), El problema del conocimiento en Nicolás de Cusa: genealogía y proyección (págs. 109-139). Buenos Aires: Biblos.

-Meis, A. (1990). La Gracia, ¿Verdad teológica en crisis? Teología y Vida 31, $227-$ 255.

-Meis, A. (2001). Antropología teológica. Aproximación a la paradoja del hombre (Segunda edición). Santiago: Ediciones Universidad Católica de Chile.

-Miller, C. L. (1990). The icon and the wall: Visio and Ratio in Nicholas of Cusa's De visione Dei. Proceeding of the American Catholic Philosophical Association (64), 86-98.

-Rahner, K. (1989). Curso fundamental sobre la fe. (R. Gabás Pallás, Trad.). Barcelona: Herder.

-Rahner, K. (1973). Gracia. Tratado teológico sobre la gracia. En K. Rahner (Dir.). Sacramentum Mundi. (Vol. III, págs. 319-33). Barcelona: Herder.

-Ruiz de la Peña, J. L. (1991). El don de Dios: Antropología teológica especial. Santander: Sal Terrae. 
Sumario: Introducción; 1. Consideraciones a la teología de la gracia en $D e$ visione Dei; 2. Teología de la gracia en De visione Dei; 2.1. Ojos de gracia; 2.1.1. Los ojos de gracia del Padre; 2.1.2. Los ojos de gracia del Hijo; 2.1.3. El Espíritu Santo y la acción graciosa del ver; 2.2. El hombre constituido por gracia; 2.3. El hombre que vive en gracia; 3. Esbozo sistemático de la gracia; Conclusión; Referencias. 